\title{
Diversity in Starvation Survival Strategies and Outcomes among Heterotrophic Proteobacteria
}

\author{
Megan Bergkessel Laurent Delavaine \\ Division of Molecular Microbiology, School of Life Sciences, University of Dundee, Dundee, UK
}

\author{
Keywords \\ Carbon starvation - Growth arrest · Proteobacteria . \\ BONCAT · Genomics
}

\begin{abstract}
Heterotrophic Proteobacteria are versatile opportunists that have been extensively studied as model organisms in the laboratory, as both pathogens and beneficial symbionts of plants and animals, and as ubiquitous organisms found freeliving in many environments. Succeeding in these niches requires an ability to persist for potentially long periods of time in growth-arrested states when essential nutrients become limiting. The tendency of these bacteria to grow in dense biofilm communities frequently leads to the development of steep nutrient gradients and deprivation of interior cells even when the environment is nutrient rich. Surviving within host environments also likely requires tolerating growth arrest due to the host limiting access to nutrients and transitioning between hosts may require a period of survival in a nutrient-poor environment. Interventions to maximise plant-beneficial activities and minimise infections by bacteria will require a better understanding of metabolic and regulatory networks that contribute to starvation survival, and how these networks function in diverse organisms.

Here we focus on carbon starvation as a growth-arresting condition that limits availability not only of substrates for
\end{abstract}

biosynthesis but also of energy for ongoing maintenance of the electrochemical gradient across the cell envelope and cellular integrity. We first review models for studying bacterial starvation and known strategies that contribute to starvation survival. We then present the results of a survey of carbon starvation survival strategies and outcomes in ten bacterial strains, including representatives from the orders Enterobacterales and Pseudomonadales (both Gammaproteobacteria) and Burkholderiales (Betaproteobacteria). Finally, we examine differences in gene content between the highest and lowest survivors to identify metabolic and regulatory adaptations that may contribute to differences in starvation survival.

(c) 2021 The Author(s)
Published by S. Karger AG, Basel

\section{Introduction}

How cells adjust their growth and biosynthetic activities in response to environmental conditions has been a question of central importance to microbiologists and molecular biologists for decades. In the case of heterotrophic Proteobacteria, rapid exponential growth in rich laboratory media has been the "standard state" for a major-

This article was contributed as a hybrid review-research article for an article collection on Bacterial Survival Strategies.
(C) 2021 The Author(s)

Published by S. Karger AG, Basel

This is an Open Access article licensed under the Creative Commons Attribution-NonCommercial-4.0 International License (CC BY-NC) (http://www.karger.com/Services/OpenAccessLicense), applicable to the online version of the article only. Usage and distribution for commercial purposes requires written permission.
Correspondence to:

Megan Bergkessel, mbergkessel001@dundee.ac.uk 
ity of studies across a range of fields, and indeed there are advantages to focussing on this physiological state. The assumptions that exponential growth is balanced (all cellular components increase proportionally) and steady state simplify mathematical modelling of biosynthetic and metabolic pathways [Dennis et al., 2004; Erickson et al., 2017]. Cells in exponentially growing populations are fairly homogeneous, meaning that population-level measurements of gene expression or metabolic activity are considered good proxies for the activities of each cell. Finally, an imposed change in conditions prompts strong and rapid responses as highly active gene expression machinery is re-directed to address the change. In contrast, starvation-induced growth arrest is characterised by low levels of activity and high population heterogeneity, necessitating sensitive measurements at a single-cell level to fully characterise responses [Hatzenpichler et al., 2020]. Against this background of low signal and high noise, differences in conditions used to starve cells can substantially affect outcomes, making comparison of results across different organisms or even different laboratories difficult. However, these difficulties do not justify neglecting ubiquitous and ecologically important starved states of bacteria. In this extended introduction, we will first discuss different models for studying starvation and their implications, then review known conserved mechanisms of starvation survival. Finally, we will introduce the organisms we have directly compared with respect to their carbon starvation survival.

\section{Models for Studying Starvation Survival}

Many different methods have been applied for achieving a carbon-starved state. Perhaps the most straightforward is simply to allow a batch culture to deplete the carbon from its growth medium. In the case of the commonly used LB medium (lysogeny broth, containing 5 $\mathrm{g} / \mathrm{L}$ yeast extract and $10 \mathrm{~g} / \mathrm{L}$ tryptone), the carbon sources are primarily amino acids and peptides which are utilised sequentially according to the ease with which they enter central metabolism. Even at relatively low optical densities (approx. 0.3 for Escherichia coli), growth rates are limited by carbon availability as cells are forced to continually adapt to the remaining complement of amino acids [Sezonov et al., 2007]. However, cultures of many different heterotrophic bacteria are able to eventually reach high optical densities of 3.0-8.0 in LB, so by the time growth stops, depletion of the carbon sources is not the only stress affecting cellular physiology. At cellular densities this high, oxygen cannot diffuse fast enough to keep up with respiration even with vigorous

Diverse Starvation Survival Strategies and Outcomes shaking, and thus is likely to be an additional limitation for aerobic organisms [Price-Whelan et al., 2007]. Furthermore, the metabolism of amino acids in LB can result in substantial changes to the $\mathrm{pH}$ of the medium (usually increasing); some organisms have been observed to alter their culture $\mathrm{pH}$ so drastically during growth in rich media that the entire population collapses [Ratzke and Gore, 2018].

For E. coli, the combined effects of these stresses have been observed to lead to death of $90-99 \%$ of the population after 2-3 days of stationary phase in LB. Interestingly, the remaining $1-10 \%$ of the population remains stable in number for months or even years without new nutrient input, and repeated mutational sweeps of the population suggest that cellular turnover is occurring [Finkel and Kolter, 1999]. The proposed explanation for this phenomenon, referred to as GASP (growth advantage in stationary phase), is that the early death of a large proportion of the population releases nutrients that can support growth and division of the surviving minority; acquired mutations improve the ability of surviving cells to cannibalise the cells that have died, and balanced birth and death of cells can be sustained over a prolonged period of time [Finkel, 2006].

This model introduces several complexities: a dynamic population structure due to mutational sweeps, heterogeneous growth and death within the population, and the fact that substantial amounts of nutrients can be released by large numbers of dying cells [Takano et al., 2017; Schink et al., 2019]. An alternative method that has been explored is to abruptly shift cells growing in exponential phase to a minimal medium lacking a carbon source, or with a low concentration of a single carbon source, at lower density than is reached in stationary phase. Under this regime, E. coli exhibit a constant death rate that can be fit to an exponential curve and correlated to the growth rate before the shift [Schink et al., 2019; Biselli et al., 2020]. Unlike the process of growing into stationary phase in LB, this model does not allow for a gradual adaptation to carbon starvation during serial depletion of several different carbon sources, and this lack of adaptation appears to impose survival costs, as the half-life of the population following a shift from LB medium is only approximately $18 \mathrm{~h}$ [Biselli et al., 2020].

A third model that has been used is to allow cells to deplete the carbon source from M9 minimal salts medium containing $1 \mathrm{~g} / \mathrm{L}$ of casamino acids as the sole carbon source, within a microfluidic device allowing individual cells to be followed [Gefen et al., 2014]. This method should allow a period of adaptation as cells sequentially 
deplete different amino acids, but prevents the stresses associated with a high-density culture as the culture density supported by this concentration of casamino acids is low. Under these conditions, a high percentage of $E$. coli cells $(80-90 \%)$ were shown to survive and to continue producing new proteins for a period of at least 2.5 days, although the rate of new protein synthesis was an order of magnitude slower than during growth [Gefen et al., 2014].

All of these studies were carried out using E. coli as a model organism. Studies of carbon starvation in other organisms have also been carried out; notably, Tn-Seq screens have identified genetic determinants of fitness during carbon starvation in Pseudomonas aeruginosa [Basta et al., 2017] and also in the photoheterotroph Rhodopseudomonas palustris [Pechter et al., 2017; Yin et al., 2019]. In both cases a minimal medium with a low starting concentration of a single carbon source was used (although $R$. palustris was also able to generate energy by photosynthesis), and most cells remained viable for an impressive length of time (30 days for $P$. aeruginosa and $>120$ days for $R$. palustris). Anecdotal reports of impressive starvation survival capabilities of various other organisms are scattered throughout the literature, but the differences in conditions used make them very difficult to directly compare [Amy and Morita, 1983; Tavares et al., 2020].

A further complication is that many organisms have been reported to enter a "viable but non-culturable" (VBNC) state during prolonged starvation, often when additional stresses such as high osmolarity, low temperature, or antibiotics are also present. The defining characteristic of cells in these states is an inability to form colonies on solid rich (i.e., LB) media, despite maintaining electrochemical gradients across their membranes [Ayrapetyan et al., 2018]. In some cases, specific treatments that resuscitate cells from VBNC states have been uncovered, allowing them to then be counted in CFU assays. However, in the absence of a resuscitation protocol, identifying and characterising VBNCs requires a specialised methodology, and much still remains to be learned [Bamford et al., 2017]. Here we used LB medium to allow growth into stationary phase, but after $24 \mathrm{~h}$, we shifted the stationary phase cells to minimal medium lacking a carbon source, at a starting density of approximately $5 \times 10^{8}$ $\mathrm{CFU} / \mathrm{mL}$. This treatment was chosen to allow for the evolved regulatory responses associated with depleting diverse carbon sources but avoid long-term exposure to the additional density and $\mathrm{pH}$-related stresses associated with stationary phase in LB. We hoped this treatment would specifically starve cells for carbon without imposing additional stresses, thus avoiding complications from VBNC states.

\section{Regulatory and Metabolic Strategies for Surviving Carbon Starvation}

Adaptations occurring during the initial nutrient downshift have been the best-studied aspect of starvation survival. While the physiology of the long-term starvation survival state is different in many ways from the physiology of cells just entering stationary phase, the adaptations that occur during this transition appear to be important for survival later [Babin et al., 2016; Basta et al., 2017; Yin et al., 2019; Biselli et al., 2020], and several global regulators that have been extensively studied in E. coli are highly conserved across the Proteobacteria. These include the stress sigma factor referred to as RpoS or $\sigma^{38}$ (recently comprehensively reviewed by Gottesman [2019]) and the mediators of stringent response: the small alarmone (p)ppGpp and DksA [Hauryliuk et al., 2015]. A great deal of elegant work over multiple decades has revealed in detail the mechanisms by which these regulators help coordinate a global repression of new biosynthesis by downregulating ribosome biogenesis, nucleotide biosynthesis, and new rounds of chromosome replication while simultaneously re-directing transcription and translation capacity towards active stress responses [Gourse et al., 2018; Gottesman, 2019; Kraemer et al., 2019; Wang et al., 2019]. Among the consequences of these adaptations are a dramatic decrease in cell size as previously initiated rounds of chromosome replication and cell division finish in the context of much-reduced biosynthesis of cellular components [Vadia and Levin, 2015; Fernandez-Coll et al., 2020].

In carbon starvation, many of the specific stress responses under the control of RpoS, DksA, and (p)ppGpp result in changes to metabolism [Zinser and Kolter, 1999; Typas et al., 2007; Sanchez-Vazquez et al., 2019]. Even if new net production of cellular components is completely repressed, greatly reducing the requirement for carbon as a biosynthetic building block, heterotrophic cells must still catabolise carbon for a source of energy to maintain the electrochemical gradient across the cell membrane and to power ATP-dependent maintenance processes essential for viability. Metabolic changes to address this challenge include improvements to the efficiency of pathways for generating ATP and proton motive force (PMF), upregulation of transporters and catabolic pathways for alternative carbon sources from the environment, and mobilisation of internal carbon stores for catabolism 
Table 1. Bacterial strains

\begin{tabular}{|c|c|c|c|}
\hline Strain & Direct source & Original source & RefSeq accession \\
\hline Acinetobacter baumannii ATCC19606 & Gift from Sarah J. Coulthurst & Human urine [Bouvet and Grimont, 1987] & GCF_009035845.1 \\
\hline Escherichia coli BW25113 & Gift from Dianne K. Newman & Wanner laboratory [Wanner et al., 1983] & GCF_015534855.1 \\
\hline Escherichia coli UTI89 & Gift from Sarah J. Coulthurst & $\begin{array}{l}\text { Uncomplicated cystitis (bladder inflammation) } \\
\text { [Chen et al., 2006] }\end{array}$ & GCF_000013265.1 \\
\hline Pectobacterium atrosepticum SCRI1043 & Gift from Sarah J. Coulthurst & $\begin{array}{l}\text { Stem of potato plant with blackleg, Scotland } \\
\text { [Bell et al., 2004] }\end{array}$ & GCF_000011605.1 \\
\hline Pseudomonas aeruginosa $\mathrm{PAO} 1$ & Gift from Sarah J. Coulthurst & Human burn wound [Holloway, 1955] & GCF_000006765.1 \\
\hline Pseudomonas aeruginosa UCBPP-PA14 & Gift from Dianne K. Newman & Human burn wound [Mathee, 2018] & GCF_000014625.1 \\
\hline $\begin{array}{l}\text { Pseudomonas chlororaphis subsp. } \\
\text { piscium PCL1391 }\end{array}$ & Gift from Dianne K. Newman & $\begin{array}{l}\text { Tomato rhizosphere, Spain [Chin-A-Woeng et al., } \\
\text { 1998] }\end{array}$ & GCF_003850445.1 \\
\hline Serratia marcescens Db10 & Gift from Sarah J. Coulthurst & Moribund Drosophila melanogaster [Flyg et al., 1980] & GCF_000513215.1* \\
\hline
\end{tabular}

[Bergkessel et al., 2016]. For example, many aerobic bacteria encode multiple terminal oxidases with distinct properties that can be upregulated under specific environmental conditions. In P. aeruginosa there are five different terminal oxidases, and one of them is upregulated by RpoS under starvation conditions. This $a a_{3}$ type cytochrome $\mathrm{c}$ oxidase (similar to the mitochondrial terminal oxidase) has a lower affinity for oxygen than any of the others but is able to pump more protons across the membrane per oxygen reduced, yielding more PMF or ATP [Arai, 2011].

Still, increases in electron transport chain efficiency are only helpful if there are some carbon sources that can be catabolised to yield electrons that can be transported. Many of the GASP mutations that confer fitness advantages during long-term stationary phase cause upregulation of amino acid transport and catabolism, which aid in the utilisation of dead cell components as a carbon source [Zinser and Kolter, 1999, 2000]. Internal storage forms of carbon, such as glycogen and polyhydroxyalkanoates, vary across organisms and can accumulate when carbon is in excess or to accommodate inconsistent availability or utilisation of carbon substrates [Prieto et al., 2016; Müller-Santos et al., 2020; Sekar et al., 2020]. Molecules accumulated as compatible solutes to manage osmotic stress, such as trehalose, choline, glycine betaine, or sarcosine can also be catabolised as carbon sources by many organisms [Wargo, 2013]. Finally, many lines of evidence suggest that cellular components like ribosomes and membrane lipids could be catabolised during starvation; genes encoding enzymes of fatty acid beta oxidation and proteases have been shown to be required for fitness and/ or upregulated during starvation in multiple organisms [Farewell et al., 1996; Basta et al., 2017; Basta et al., 2020].

Although new protein synthesis occurs at much slower average rates during starvation compared to growth [Bergkessel, 2020], it has been shown to be required for optimal survival [Yin et al., 2019]. Replacement of damaged proteins and responding to new environmental threats or opportunities are likely important functions of this low-level new protein synthesis. While much still remains to be learned, recent evidence suggests that some global regulators of transcription and translation may play important roles in facilitating low-level expression of essential genes during starvation. For example, BONCAT (bio-orthogonal non-canonical amino acid tagging, a method to label and enrich for proteins that were newly synthesised during a defined period), applied during oxygen starvation in $P$. aeruginosa, identified translation elongation factor $\mathrm{P}$ (Efp) and a factor that enhances transcription of multiple housekeeping genes (SutA) [Babin et al., 2016]. The precise roles of the major regulators of the transition to stationary phase, RpoS and DksA/(p)ppGpp, during protracted starvation also remain to be determined [Bergkessel et al., 2016; Yin et al., 2019]. 
Evolutionary Pressures Shaping Survival Strategies of Diverse Organisms

Under carbon starvation stress, bacterial regulatory strategies must either decrease activity to the greatest extent possible to best conserve limited resources, or maintain some ongoing metabolic activity to increase responsiveness to the environment [Bergkessel, 2020]. Which strategy produces the best outcome will depend on many unpredictable factors: the length of the starvation period, stochastic threats or opportunities during starvation, and the amount of competition upon arrival of new nutrients, for example. While many bacteria have "bet-hedging" mechanisms for improving their chances by increasing population heterogeneity during starvation to adopt multiple strategies simultaneously [Moreno-Gamez et al., 2020], the evolutionary histories of bacterial species might be expected to push their regulatory and metabolic networks towards favouring more or less active approaches to dealing with protracted starvation. For example, free-living oligotrophs that have spent much of their evolutionary history in low-nutrient environments might be more likely to favour an active approach to dealing with starvation, extracting all possible nutrients out of their environments, and remaining ever-ready to take advantage of brief opportunities for growth [Hobbie and Hobbie, 2013]. On the other hand, organisms that have evolved to have close symbiotic, commensal, or pathogenic relationships with plant or animal hosts, with exposures to low-nutrient environments between hosts, might favour a more conservative approach to starvation, saving resources for the activities needed to colonise a new host [Asakura et al., 2007].

To explore these possibilities, we examined the carbon starvation survival strategies of 10 different strains of Proteobacteria: four members of the Pseudomonadales order, five members of the Enterobacterales (Gammaproteobacteria), and one Burkholderiales (a Betaproteobacterium; Table 1; Fig. 1b). We chose these organisms because they represent a range of isolation sources and lifestyles, they all grow well in LB Lennox medium at $30^{\circ} \mathrm{C}$, and we hoped that their degree of evolutionary relatedness might allow us to gain some insight into possible genetic determinants of different survival outcomes. All of the organisms except E. coli BW25113, Pectobacterium atrospecticum SCRI1043, and $P$. chlororaphis PCL1391 are capable of causing infections in humans; $E$. coli BW25113 is a laboratory strain that has been selected for a lack of pathogenicity [Wanner et al., 1983], while $P$. atrospecticum is a plant pathogen [Bell et al., 2004] and $P$. chlororaphis has been described as a beneficial biocontrol strain for tomato plants [Chin-A-Woeng et al., 1998]. Only Salmonella enterica ser. Typhimurium and E. coli UTI89 have been observed to cause infections in otherwise healthy adults: $S$. Typhimurium causes a self-limiting gastrointestinal infection [Siddiqee et al., 2020] and $E$. coli UTI89 is a representative uropathogenic strain causing urinary tract infections [Chen et al., 2006]. The remaining organisms (both strains of $P$. aeruginosa [Dettman and Kassen, 2020], Burkholderia cenocepacia H111 [Loutet and Valvano, 2010], Acinetobacter baumannii ATCC19606 [Harding et al., 2018], and Serratia marcescens Db10 [Flyg et al., 1980]) are considered opportunistic pathogens, capable of causing infections in a wide range of plant and animal hosts, including immune-compromised humans, but also capable of living independently in the environment.

\section{Results and Discussion}

In order to directly compare survival strategies and outcomes among the 10 Proteobacterial species and strains, we grew each of them to stationary phase over $24 \mathrm{~h}$ in LB Lennox medium (containing $5 \mathrm{~g} / \mathrm{L}$ sodium chloride, in contrast to the $10 \mathrm{~g} / \mathrm{L}$ contained in the Miller formulation), then shifted cells to a minimal medium containing all essential nutrients except a carbon source (time $=0$ ) and monitored colony-forming units per volume $(\mathrm{CFU} / \mathrm{mL})$ over 31 days. We also followed changes in cell size and morphology by phase contrast microscopy during exponential growth in LB Lennox medium, at the stationary phase switch from LB to minimal medium, after 3.5 days of starvation in minimal medium, and after 32 days of starvation. Finally, we estimated protein biosynthetic activity during $24 \mathrm{~h}$ of starvation, starting after either 2.5 days or 28 days, using the BONCAT metabolic labelling method [Dieterich et al., 2007]. Diverse survival phenotypes and outcomes were observed, prompting us to examine the genomes of the species and strains for possible genetic contributors to the differential outcomes.

\section{Differential Survival Outcomes}

The percent of bacteria surviving 31 days of carbon starvation varied over three orders of magnitude, from approximately $100 \%$ in the case of $B$. cenocepacia to approximately $0.1 \%$ in the case of $A$. baumannii (Fig. 1 ). The second-highest fractional survival was seen in the rhizosphere biocontrol strain P. chlororaphis (approx. 75\% remaining after 31 days), followed next by the two other members of its genus, the $P$. aeruginosa strains (40 and 


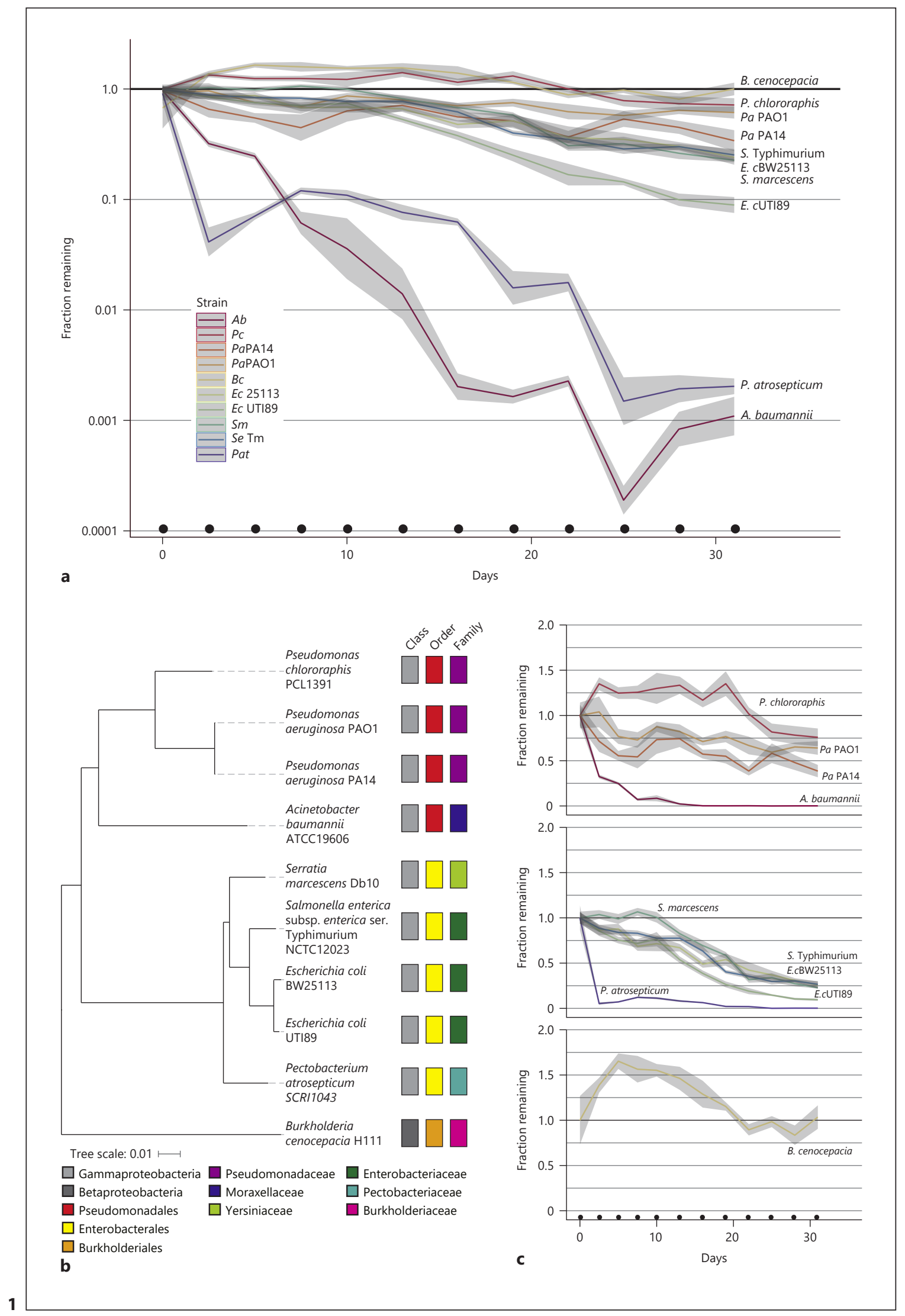

(For legend see next page.) 
$60 \%$ remaining for UBCPP-PA14 and PAO1, respectively). Among the Enterobacterales, $P$. atrosepticum showed the lowest survival with only $0.3 \%$ remaining at 31 days. S. marcescens showed the highest survival in the first half of the time course, but by the end of the experiment showed very similar survival to the lab strain E. coli BW25113 and S. Typhimurium (which showed similar survival patterns throughout) at about $25 \%$. The uropathogenic strain, E. coli UTI89, showed substantially lower survival than its Enterobacteriaceae cousins, with $10 \%$ remaining by the end of the experiment.

Broadly, we can summarise the trend at the family level as follows: our representative of the Burkholderiaceae had the highest fraction of its starting population survive the 31-day time course, followed by the Pseudomonadaceae, the Yersiniaceae, and Enterobacteriaceae; the Pectobacteriaceae and Moraxellaceae had the lowest fractions of their starting populations survive. However, comparing within and across families yields some additional observations. For both $P$. aeruginosa and E. coli, we tested two representative strains. In each case, one strain is widely considered to be more acutely virulent than the other [Chen et al., 2006; Dettman and Kassen, 2020]. For $P$. aeruginosa, the UCBPP-PA14 genome contains pathogenicity islands that are not found in PAO1, as well as mutations in multiple global regulators leading to higher levels of expression of known virulence factors such as elastase and the redox-active pigment pyocyanin [He et al., 2004]. For E. coli, the uropathogenic strain UTI89 is distinguished from the lab strain BW25113 by a large pathogenicity island as well as a plasmid, in addition to many additional small changes in gene content [Chen et al., 2006]. For both $P$. aeruginosa and E. coli, survival was higher for the less acutely virulent strain than for the more virulent strain. In general, virulence factors may bring no benefit to the strains that encode them under the starvation conditions tested but may have energetic or toxicity costs.

Fig. 1. Survival of 10 Proteobacteria strains over 31 days of carbon starvation. a CFU at each time point were plotted as a fraction of the mean starting value at time $=0$ (transfer into minimal media lacking a carbon source) for the replicate cultures for each strain. Grey ribbon indicates standard error, $n=7$ except the day 5 timepoint ( $n=4$ for all strains) and B. cenocepacia time course $(n=5$ after day 10). Black dots indicate timepoints at which CFU were calculated. b Phylogenetic tree and taxonomic grouping of strains used based on $16 \mathrm{~S}$ rRNA. The tree was generated by TYGS server and nodes flipped for display convenience on the iTOL server. c Survival data separated by taxonomic order and plotted on a linear scale for improved clarity of some details obscured in $\mathbf{a}$.
We were somewhat surprised by the finding that survival of A. baumannii and P. atrosepticum was much lower than the other strains tested, as both organisms are considered to have a high ability to persist in their environments. Interestingly, both organisms have previously been observed to secrete carbon-containing metabolites into their environments at the entry to stationary phase [Gorshkov et al., 2017; Zeidler and Müller, 2020]. These activities have been proposed to contribute to strategies for tolerating desiccation [Zeidler and Müller, 2019] (A. baumannii does have a remarkable ability to survive desiccation [Harding et al., 2018]) or for preparing for plant infection [Gorshkov et al., 2017]. However, under the particular conditions of this experiment, where the stationary phase culture medium was removed and a long-term carbon starvation followed, jettisoning carbon resources at the beginning of the starvation may have been maladaptive. It also remains possible that the low CFUs recovered for A. baumannii reflect a VBNC state, as although many cells appear less phase dense, there is little evidence of mass lysis of cells in the phase-contrast images we took at the end of the time course (online suppl. Fig. S1; see www. karger.com/doi/10.1159/000516215 for all online suppl. material). We tried diluting an aliquot of the culture 10fold in PBS and incubating for $16 \mathrm{~h}$ at $30^{\circ} \mathrm{C}$ before plating at the end of the time course, as a similar treatment was previously reported to resuscitate A. baumannii VBNCs formed in response to osmotic stress [Zeidler and Müller, 2020], but we saw no change in CFUs compared to plating directly from the culture (data not shown). Micrographs from the end of the time course did show extensive cell lysis for P. atrosepticum (online suppl. Fig. S1) so the low $\mathrm{CFU} / \mathrm{mL}$ in this strain do appear to be explained by death and lysis.

\section{Changes in Size during and after Transition to \\ Starvation State}

It has long been appreciated that cell size correlates with growth rate in many bacterial species, and many researchers have noted that cells in carbon starvation are much smaller than actively growing cells [Amy and Morita, 1983; van Overbeek et al., 1995]. In order to be able to normalise all starvation cultures in carbon-free minimal medium to the same number of starting $\mathrm{CFU} / \mathrm{mL}$, we measured $\mathrm{CFU} / \mathrm{mL}$ in LB stationary phase and found that the values varied over almost an order of magnitude (Fig. 2b). As the optical densities of the cultures were mostly fairly similar, this prompted us to wonder whether the sizes of cells in LB stationary phase differed greatly among organisms. We used phase-contrast microscope 


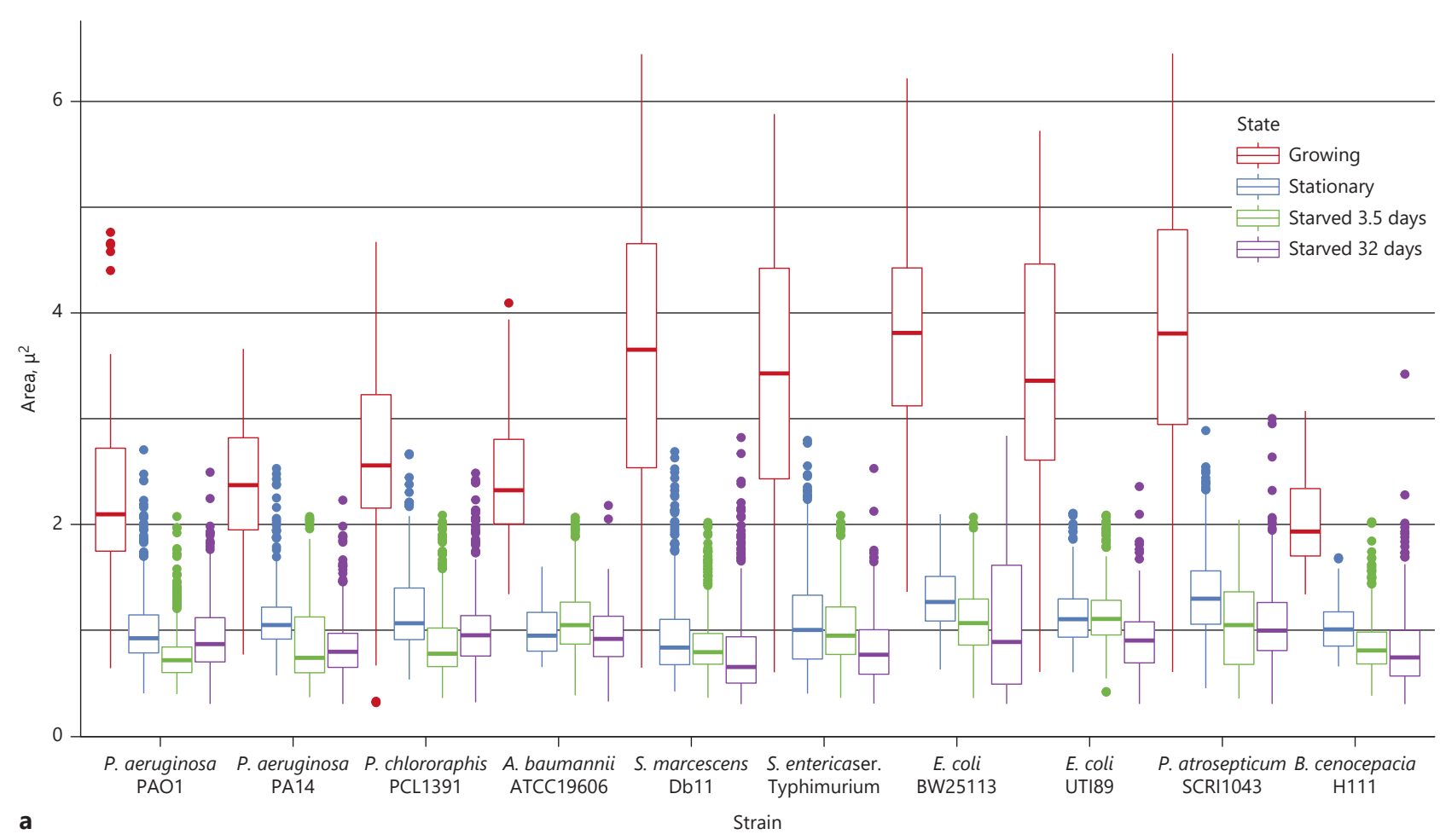

a

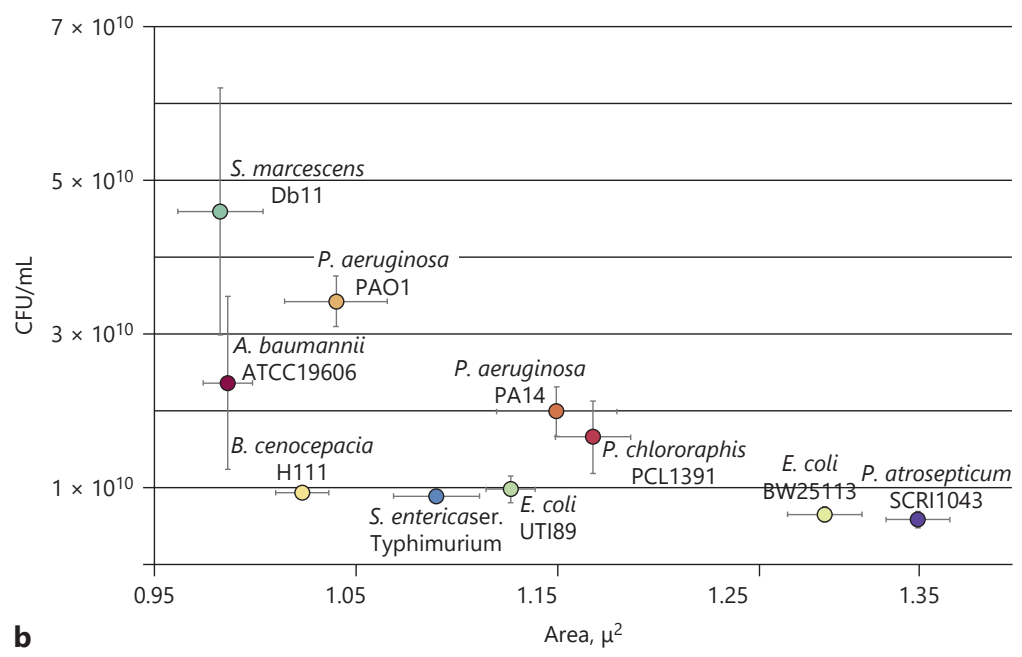

Fig. 2. Cell sizes during growth and starvation. a The areas of the phase-contrast micrographs of individual cells from each strain were calculated using the MicrobeJ plug-in for the ImageJ analysis package. The growing, stationary phase, and day 32 data were collected from live cells, while the day 3.5 data were collected from the fixed cells and fluorescently stained cells from the BONCAT experiment (Fig. 3). Boxes represent the twenty-fifth and seventy- fifth percentiles, and whiskers represent an additional $1.5 \times$ the interquartile range. Points denote outliers. Representative images from each organism and timepoint are shown in online supplementary Fig. S1. b The mean areas calculated in a are plotted versus CFU/mL in stationary phase. Error bars denote standard error of the mean, $n=3$ for CFU/mL calculation and $n=162-565$ for cell areas. 
images and the MicrobeJ plugin for Image J analysis software [Ducret et al., 2016] to measure the two-dimensional micrograph areas of cells from each strain during exponential growth, LB stationary phase, and after 3.5 or 32 days of starvation. We confirmed as expected that all cells become dramatically smaller in stationary phase compared to exponential growth. We next compared the sizes in each condition and starvation trends across the organisms. The average sizes of cells in exponential growth varied substantially and appeared to correlate with phylogeny, with cells of the Enterobacterales order exhibiting the largest areas, cells of the Burkholderiales order the smallest, and Pseudomonadales cells in between. The areas of stationary phase cells were more similar across all the organisms and did not correlate as well with phylogeny (Fig. 2a). However, we still observed some variation in cell sizes in LB stationary phase, and these size differences could contribute to the differences in $\mathrm{CFU} / \mathrm{mL}$ in this condition, as average cell areas and $\mathrm{CFU} / \mathrm{mL}$ were weakly anti-correlated across the organisms (Fig. 2b).

It remains an open question whether the dramatic decrease in cell size associated with growth arrest is due entirely to reductive divisions during the entry to stationary phase, or whether starvation-induced catabolism of cellular components can contribute significantly to further decreases in cell size. To gain some insight into this question, we compared cell sizes in LB stationary phase to the sizes observed at the end of the 32-day carbon starvation period. In almost all cases, cells at the end of the starvation period were smaller on average than at the beginning of the carbon starvation period, in LB stationary phase. For $B$. cenocepacia and $P$. chlororaphis, reductive divisions could still contribute to this later reduction in size, as the $\mathrm{CFU} / \mathrm{mL}$ for these organisms increased early in the starvation time course, suggesting that some divisions still occurred. However, for the other organisms, there is no clear evidence that divisions occurred, but cell sizes still decreased. Some of the organisms may have had substantial numbers of non-viable cells present in the images taken on day 32, and these could be smaller in size due to leakage of their contents following collapse of cell envelope integrity (online suppl. Fig. S1). Further investigation will be required to determine whether catabolism of internal stores during starvation in any of these organisms can directly contribute to decreases in cell size in the absence of cell divisions. More broadly, open questions remain regarding cell size regulation during the entry to stationary phase in diverse organisms. Recent work in $E$. coli has detailed connections between cell size regulation and carbon metabolism, in particular fatty acid biosyn- thesis, mediated by the small alarmone (p)ppGpp [Vadia et al., 2017; Westfall and Levin, 2018]. This work has focussed on regulation at different growth rates imposed by different carbon sources; in the transition to growth arrest, the cell size dynamics will depend on relative rates of new protein and lipid biosynthesis, initiation of new chromosome replication, and cell division as all of these processes are strongly repressed to near zero. Our finding that cell sizes and culture densities differ substantially across organisms throughout the transition from growth to starvation suggest that these organisms employ different strategies for coordinating growth arrest. At least under the conditions we examined, none of the size parameters we measured correlated well with the fraction of cells that survived starvation.

\section{Differential Protein Synthesis Activity during \\ Starvation}

Many lines of evidence from multiple organisms suggest that new protein synthesis still occurs during starvation-induced growth arrest and can be important for survival [Babin et al., 2016; Yin et al., 2019]. To directly measure low levels of new protein synthesis during carbon starvation in all of our test organisms, we took advantage of a metabolic labelling strategy referred to as BONCAT. This strategy makes use of a non-canonical amino acid analogue, L-azidohomoalanine (AHA), which is imported into bacterial cells and can be incorporated by the native translational machinery in place of methionine. AHA incorporation into new proteins introduces azide moieties, and after cells are fixed, a strain-promoted azidealkyne cycloaddition (SPAAC) reaction with a cyclooctyne-functionalised fluorophore can result in labelling of each bacterial cell that is proportional to its protein synthesis activity during its exposure to AHA (Fig. 3a) [Dieterich et al., 2007; Hatzenpichler et al., 2020]. This method has the advantage of detecting only proteins that were made during the AHA labelling period, even if they are a small fraction of the total cellular proteome. Additionally, low average rates of protein synthesis can be compensated by longer labelling periods, so a very wide range of protein synthesis rates can lead to per-cell fluorescence levels that are detectable within the dynamic range of a standard widefield fluorescence microscope (Fig. 3b, c). After 2.5 days of starvation, we labelled cells from each organism for $24 \mathrm{~h}$, calculated mean fluorescence levels per cell for 600-1,500 cells, and plotted the population distribution of fluorescence intensities. We also labelled representatives from each order (four organisms) in our study for 30 min during growth in minimal media with 


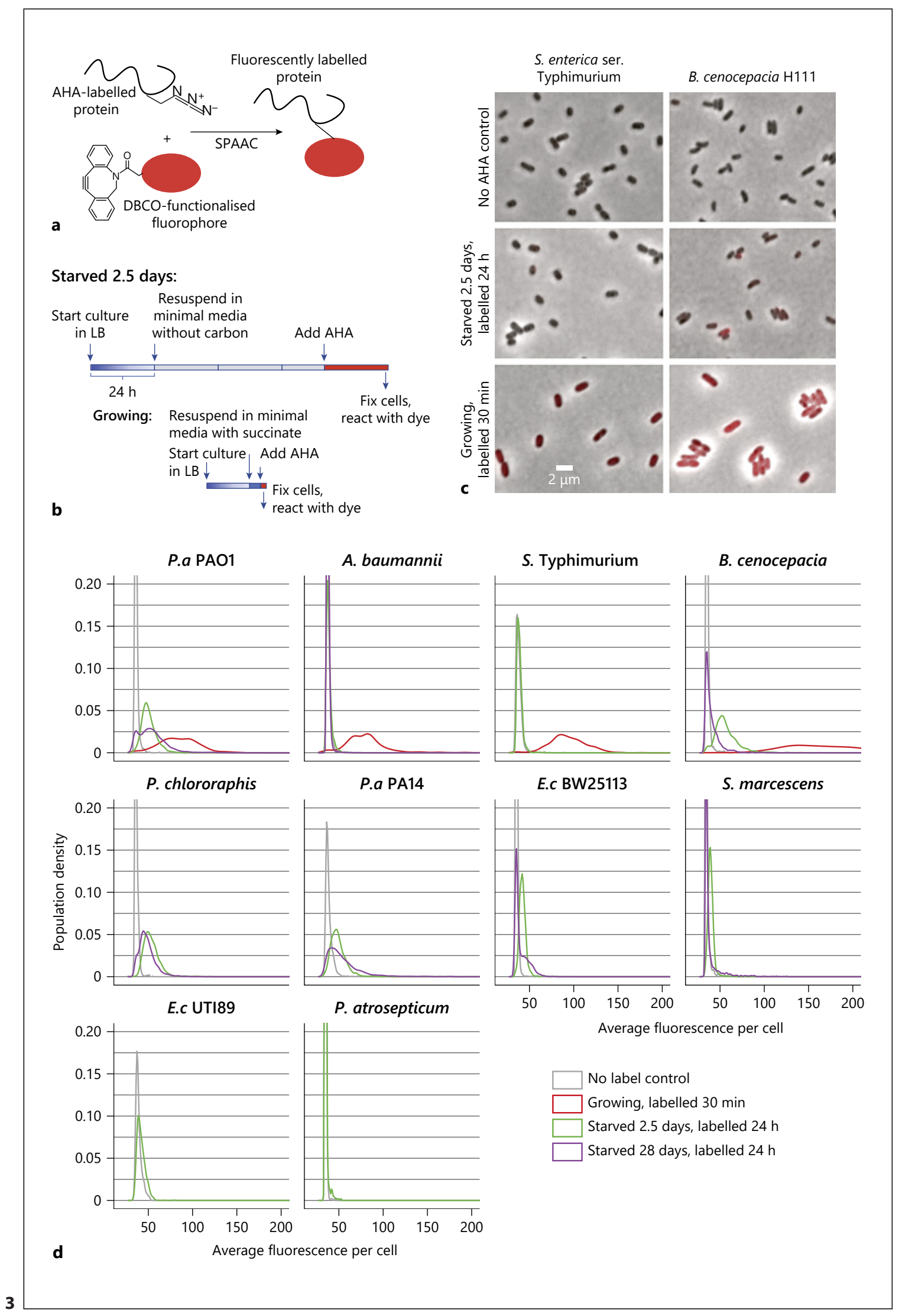

(For legend see next page.)

Diverse Starvation Survival Strategies and Outcomes
Microb Physiol 2021;31:146-162 DOI: $10.1159 / 000516215$ 
succinate (or succinate plus glucose for $S$. Typhimurium) as a carbon source. Finally, for seven of the organisms we also labelled for $24 \mathrm{~h}$ cells that had been starved for 28 days (Fig. 3d; online suppl. Fig. S2).

First, we found that the representative organisms we examined during growth were all able to robustly incorporate AHA into new proteins and become fluorescently labelled (Fig. 3d, top row). In contrast, amounts of new protein synthesis during starvation varied widely across the organisms in the study. The organisms showing the highest survival, including B. cenocepacia and the Pseudomonadaceae, all showed robustly detectable protein synthesis after 2.5 days of starvation, and while the activity was lower after 28 days of starvation, it was still detectable. The rates were much lower than during growth; the lower average per-cell pixel fluorescence values directly observed in the starved cells by microscopy must be considered in conjunction with their smaller cell sizes and the approximately 50 -fold longer labelling period, yielding estimates of per-cell protein synthesis $2-3$ orders of magnitude slower than during growth.

In contrast to the organisms showing the highest rates of survival, the organisms with the lowest survival ( $A$. baumannii, P. atrosepticum, and E. coli UTI89) showed little new protein synthesis even after only 2.5 days of starvation. However, the correlation between protein biosynthetic activity during starvation and starvation survival was not perfect. For example, $S$. Typhimurium displayed essentially no detectable protein biosynthesis after 2.5 days of starvation (we did not attempt to measure activity after 28 days of starvation) while E. coli BW25113 showed substantial activity after 2.5 days and a subpopu-

Fig. 3. BONCAT labelling to measure protein synthesis per cell during carbon starvation. a BONCAT labelling schematic. The native protein biosynthetic machinery incorporates AHA, thus incorporating azides into newly synthesised proteins. Following fixation of cells that had incorporated AHA, an SPAAC reaction can covalently attach a DBCO-functionalised fluorophore to newly synthesised proteins. b Time courses of labelling experiments. c Representative microscopy showing no AHA controls, starving, and growing cells for $S$. Typhimurium and B. cenocepacia. Phasecontrast and AF555 fluorescence channels are overlaid. d Population distributions of per-cell mean fluorescence values measured from micrographs like those shown in c. Data are from one of the two biological replicates that was performed, and the labelling replicates that were performed for each condition are combined. $n=$ $323-660$ for growing cells, approximately $600-1,500$ per labelling replicate for starved cells. Protein synthesis was measured in growing cells only for the four representative strains shown in the top row. All labelling and biological replicates for starved cells are shown separately in online supplementary Figure S2. lation that was still active after 28 days. Nevertheless, the survival patterns of $S$. Typhimurium and E. coli BW25113 were nearly identical. Likewise, $S$. marcescens shows lower activity than $E$. coli BW25113, but significantly higher survival during the first half of the time course.

Interestingly, three of the organisms displaying very low protein biosynthetic activity during starvation ( $S$. Typhimurium, E. coli UTI89, and P. atrosepticum) are considered true pathogens, able to infect healthy hosts (humans for the first two, potato plants for the third). Perhaps this evolutionary history has indeed favoured a regulatory strategy of low activity during starvation, which would tend to occur in environments outside preferred hosts. This strategy could conserve energy and substrate stores for use when external signals indicate that a new host has been encountered. A. baumannii, which also displayed very low levels of activity, is considered an opportunistic pathogen, but no environmental reservoir that is not associated with animal hosts or hospital environments has been identified [Antunes et al., 2014]. Perhaps this organism also prefers to conserve its biosynthetic resources for use after contacting a new host. We conclude that at least among the organisms we examined, higher protein biosynthesis during starvation tends to be associated with bacteria that are opportunistic generalists and that survived our starvation condition well. Meanwhile, low biosynthetic activity during starvation is associated with organisms that might be considered more dedicated pathogens, and that showed lower starvation survival rates in our experiment. Much more work will be required to determine whether these generalisations hold over a wider range of organisms, and to uncover mechanisms by which these patterns emerge.

\section{Comparative Genomics to Identify Genes Correlated with Survival Outcomes}

Our systematic observations of survival during 1 month of carbon starvation and new protein synthesis during starvation revealed intriguing differences among several Gammaproteobacteria and 1 Betaproteobacterium that did not correlate perfectly with phylogeny. This raised the possibility that insights into genetic determinants of activity and survival during carbon starvation could be suggested by comparative genomic analysis. There are caveats to this analysis; activity and survival are likely determined by broad networks of metabolic and regulatory factors, including subtle aspects of their architectures that are invisible to analysis of gene presence or absence. Furthermore, the number of genomes we can compare among the highest- and lowest-survival out- 
comes in our dataset is obviously small. Nevertheless, we performed two analyses using reciprocal best blast to search for interesting patterns of gene presence/absence across genomes in our dataset. First, we identified genes that had clear homologs in the genomes of each of the four highest-survival organisms (the three Pseudomonadaceae and B. cenocepacia) but did not have clear homologs in the rest of the organisms. We hoped that this comparison might be illuminating since the three pseudomonads are more closely related to the rest of the organisms than to $B$. cenocepacia, so are not expected to share genes in common with $B$. cenocepacia but not the others on the basis of lineage alone. We also identified

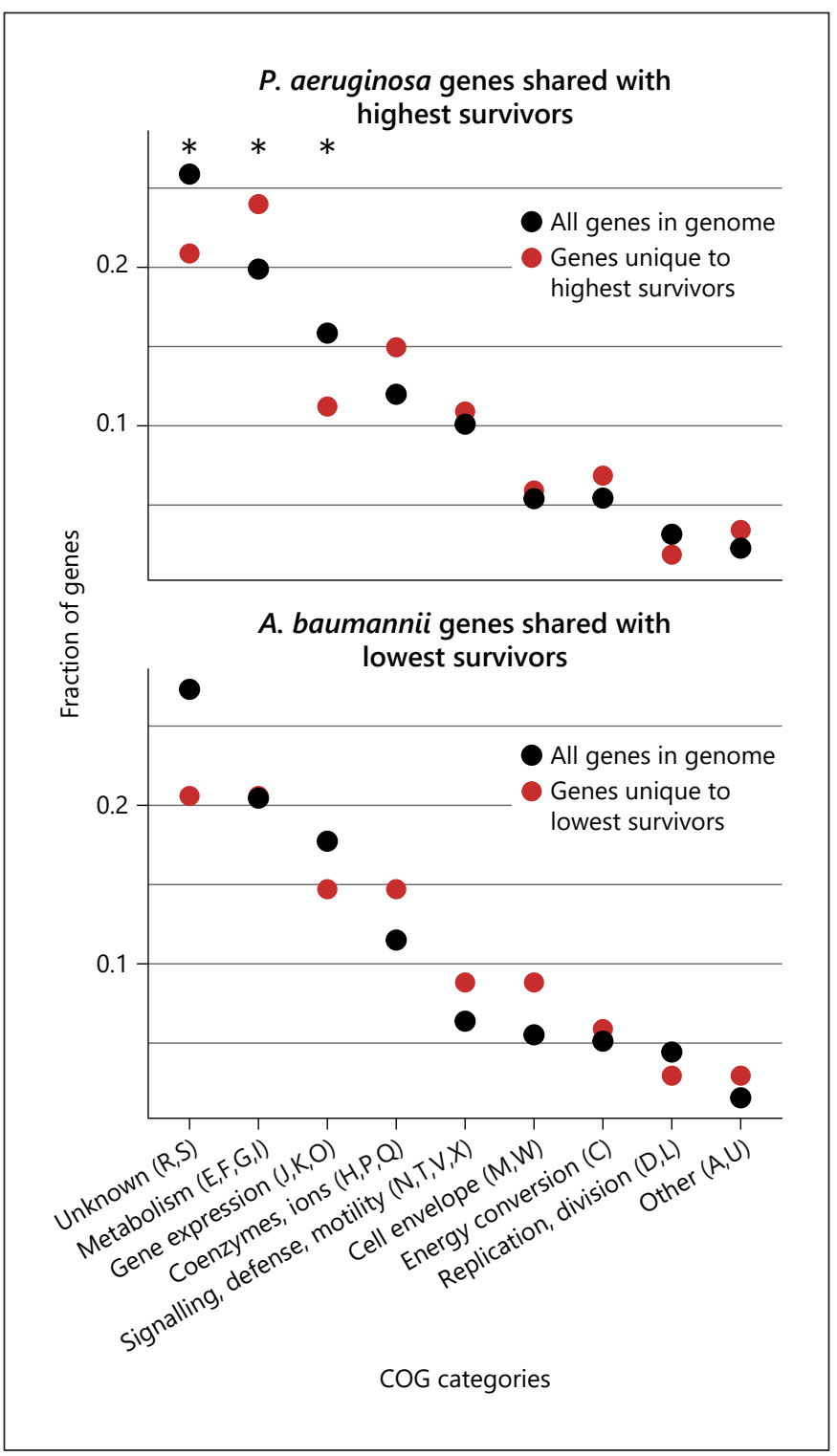

Diverse Starvation Survival Strategies and Outcomes genes with clear homologs in each of the three lowestsurvival organisms (A. baumannii, P. atrosepticum, and E. coli UTI89) but no clear homologs in the two highestsurvival organisms (B. cenocepacia and P. chlororaphis).

We identified 321 genes with clear homologs in the genomes of the highest survivors but not in the genomes of the other organisms and determined their COG categories [Galperin et al., 2020] to get a broad sense of their functions. The most overrepresented categories among genes unique to the highest-survival organisms (relative to their fractions of genes in the PAO1 genome) include genes involved in carbon, amino acid, lipid, and nucleotide metabolism (summarised as "metabolism"); coenzyme, secondary, and inorganic ion metabolism ("coenzymes, ions"); and energy conversion. In contrast, the categories most overrepresented among the genes unique to the lowest-survival organisms (relative to their fractions of the A. baumannii genome) were coenzyme, secondary, and inorganic ion metabolism; signalling, de-

Fig. 4. Functional categories of genes shared only by the highestsurvival strains or only by the lowest-survival strains, compared to functional categories of all genes in representative genomes. Genes present only in the highest-survival strains (all three pseudomonad strains plus B. cenocepacia) but not in any of the other strains were identified by reciprocal best blast of $P$. chlororaphis protein sequences against each of the other genomes in the study. Likewise, genes present only in the lowest-survival strains ( $A$. baumannii, $P$. atrosepticum, and E. coli UTI89) but not in B. cenocepacia or $P$. chlororaphis were identified (see online suppl. Tables S1, S2). Next, the fractions of these lists that fell into each functional category were determined (red symbols). These were compared to the fractions of the whole genomes of representative highest- and lowest-survival strains (chosen based on their presence in the COG database) that fell into each category to identify over- and underrepresented categories. The categories were defined by combining functional categories from COG designations. Function unknown $=\mathrm{R}$ (general prediction only) and S (function unknown) plus genes with no COG assigned; metabolism $=\mathrm{E}$ (amino acid transport and metabolism), F (nucleotide transport and metabolism), G (carbohydrate transport and metabolism), and I (lipid transport and metabolism); gene expression $=\mathrm{J}$ (translation, ribosome structure), $\mathrm{K}$ (transcription), and $\mathrm{O}$ (post-translational modification and protein degradation); coenzymes, ions $=\mathrm{H}$ (coenzyme transport and metabolism), P (inorganic ion transport and metabolism), and Q (secondary metabolites biosynthesis); signalling, defence, motility = N (cell motility), $\mathrm{T}$ ( signal transduction mechanisms), V (defence mechanisms), and X (mobilome); cell envelope $=\mathrm{M}$ (cell wall $/$ membrane/envelope $)$ and $\mathrm{W}$ (extracellular structures); energy conversion $=\mathrm{C}$; replication, division $=\mathrm{D}$ (cell cycle control and chromosome partitioning) and L (replication, recombination and repair); other $=\mathrm{A}$ (RNA processing and modification) and $U$ (intracellular trafficking). Statistically significant over- or underrepresentation as determined by the hypergeometric test, ${ }^{*} p<0.05$. 
fence, and motility; and cell envelope (Fig. 4a; online suppl. Tables S1, S2). Specialised functions in signalling, defence, motility, and cell envelope modifications might be important for interactions with host organisms, but less helpful during starvation for carbon as a pure culture.

One striking example of genes from the energy conversion category is the multi-subunit $a a_{3}$-type cytochrome $c$ oxidase. This is the terminal oxidase variant that has been shown in $P$. aeruginosa to be upregulated during nutrient limitation and that can more efficiently pump protons than other terminal oxidases, at the cost of having a lower oxygen affinity [Arai, 2011]. It is apparently also found in $P$. chlororaphis and B. cenocepacia, but in none of the other bacteria we tested. In a previous Tn-Seq-based study of genetic determinants of fitness during carbon starvation, it was identified as conferring a strong fitness benefit in $P$. aeruginosa - evidence that the presence of this complex is not only correlated with better survival of carbon starvation across multiple organisms, but it also directly contributes to better survival of $P$. aeruginosa [Basta et al., 2017]. Another set of genes that are common to the pseudomonads and B. cenocepacia but not found in the other organisms are genes for the aerobic synthesis of vitamin B12 (cobalamin). P. aeruginosa cobalamin biosynthesis has previously been suggested to be oxygen dependent [Lee et al., 2012]. Some of the other organisms in our study (E. coli, P. atrosepticum, S. marcescens, A. baumannii) cannot synthesise cobalamin de novo and instead must scavenge it (or its precursors) from the environment, while others ( $S$. Typhimurium) possess an anaerobic biosynthetic pathway for this cofactor precursor [Rodionov et al., 2003]. A biosynthetic pathway for this cofactor in the pseudomonads and B. cenocepacia that requires oxygen is perhaps in keeping with the generally aerobic lifestyles of these organisms, which has also selected for a terminal oxidase that can sacrifice oxygen affinity for increased proton pumping efficiency.

Genes involved in catabolism of compatible solutes and other carbon stores, including polyhydroxyalkanoates, trehalose, sarcosine, and glycine betaine, were also among those with clear homologs in the pseudomonads and $B$. cenocepacia but not the other organisms. For trehalose, there are multiple described pathways leading to catabolism, and only one of them (the conversion of trehalose to maltose by the product of the treS gene) was unique to the pseudomonads and B. cenocepacia [Ruhal et al., 2013]. Genes in specific pathways for amino acid catabolism, such as the branched-chain amino acid dehydrogenase operon, were also among this group [Kazakov et al., 2009]. The utility of specific carbon, amino acid, and lipid metabolic pathways for surviving a starvation condition depends in part on the specific nutrients available before and during the starvation. All of the organisms we investigated possess diverse metabolic pathways for scavenging and catabolising carbon from both environmental and internal sources, but our analysis suggests that the highest-survival organisms possess several examples of additional pathways that the other organisms lack.

Although regulators of transcription and translation were underrepresented among the genes that were uniquely present in the highest- and lowest-survival organisms (Fig. 4), we noticed a few examples of regulators with interesting distributions among the organisms we examined. One involves modification of the translation elongation protein Efp, which is found in all the organisms in our study. Efp was shown to be relatively more highly expressed during anoxia-induced growth arrest in $P$. aeruginosa compared to growth, suggesting an ongoing requirement for its activity under this condition [Babin et al., 2016], and several studies have shown that post-translational modification of this protein is required for its function. Interestingly, the modification that occurs is different in different organisms: in E. coli, lysine 34 is $\beta$-lysinylated and then hydroxylated by EpmA and EpmC, respectively, while in $P$. aeruginosa the homologous residue arginine 32 is rhamnosylated by EarP [Rajkovic and Ibba, 2017]. The earP gene was found in $B$. cenocepacia and $P$. chlororaphis too, and thus is present in organisms that maintained high levels of ongoing protein synthesis during growth arrest, as well as the highest survival. Meanwhile the epmAC genes were found in the lowest-survival organisms ( $P$. atrosepticum and A. baumannii) as well as in E. coli.

We also looked closely at some of the known regulators of gene expression in carbon starvation and growth arrest. For example, CbrB, a two-component response regulator with a known role in $P$. aeruginosa in de-repressing expression of catabolic genes for non-preferred carbon sources (including branched-chain amino acids) [Sonnleitner et al., 2012], was also found in P. chlororaphis and B. cenocepacia but not the rest of the organisms. Additionally, while the stringent response regulator DksA is conserved in all of the organisms we examined, half of the organisms encoded at least one additional copy of DksA, a gene described as DksA2 in P. aeruginosa. In addition to the pseudomonads and $B$. cenocepacia, this group also includes $S$. marcescens, which survived better than the other Enterobacterales in the first half of the time course. A feature of DksA2 is that it does not require a structural zinc ion for its function, and in $P$. aeruginosa it 
is upregulated under conditions of zinc starvation [BlabyHaas et al., 2011]. Finally, it has previously been reported that the regulation of levels of the stress sigma factor RpoS is different between $P$. aeruginos $a$ and $E$. coli, with a greater contribution of protein stability regulation in E. coli and a greater emphasis on transcriptional regulation in $P$. aeruginosa [Venturi, 2003]. Consistent with this, we found the anti-adaptor proteins that block proteolysis of RpoS under various stress conditions (e.g., IraP) [Gottesman, 2019] only in the Enterobacterales. Understanding how subtle differences in the conserved regulatory networks that are known to be important during growth arrest contribute to differences in survival outcomes will be a focus of ongoing research.

\section{Conclusions}

Heterotrophic Proteobacteria have evolved many strategies to survive the nutrient deprivation and other stresses that they frequently encounter in their natural environments. We conducted an exploratory survey of survival outcomes during carbon starvation for ten different Proteobacterial strains, and found that overall survival, changes to cell size, and protein biosynthetic activity during starvation varied substantially among the strains. Importantly, this suggests that these traits have been shaped by differential selective pressures in the diverse niches occupied by the strains we examined, and that they can be actively modulated by metabolic and regulatory responses to the starvation condition. Furthermore, we identified several genes that correlated with the highest and lowest survival rates over our 31-day experiment. These genes are embedded in complex regulatory networks and further investigation will be required to determine if and how they might directly contribute to starvation survival. Nevertheless, our survey illuminates an intriguing diversity of survival outcomes and strategies and motivates work to better understand the mechanistic underpinnings of this diversity.

\section{Materials and Methods}

\section{Bacterial Strains}

Information regarding the bacterial strains are presented in Table 1.

Bacterial Growth Conditions and Media

Bacterial stocks were grown using LB Lennox medium (5 g/L yeast extract, $10 \mathrm{~g} / \mathrm{L}$ tryptone, $5 \mathrm{~g} / \mathrm{L} \mathrm{NaCl}$, with $15 \mathrm{~g} / \mathrm{L}$ agar added for solid medium). For starvation time courses, a minimal salts medium with no carbon source was used $\left(6.25 \mathrm{~g} / \mathrm{L} \mathrm{K}_{2} \mathrm{HPO}_{4}, 1.93\right.$ $\mathrm{g} / \mathrm{L} \mathrm{KH}_{2} \mathrm{PO}_{4}, 2.5 \mathrm{~g} / \mathrm{L} \mathrm{NaCl}, 0.5 \mathrm{~g} / \mathrm{L} \mathrm{NH}_{4} \mathrm{Cl}, 1 \mathrm{mM} \mathrm{MgSO}, 100 \mu \mathrm{M}$ $\mathrm{CaCl}_{2}$, and trace metals: $7.5 \mu \mathrm{M} \mathrm{FeCl}_{2} \cdot 4 \mathrm{H}_{2} \mathrm{O}, 0.8 \mu \mathrm{M} \mathrm{CoCl}{ }_{2} \cdot 6 \mathrm{H}_{2} \mathrm{O}$, $0.5 \mu \mathrm{M} \mathrm{MnCl}_{2} \cdot 4 \mathrm{H}_{2} \mathrm{O}, 0.5 \mu \mathrm{M} \mathrm{ZnCl}_{2}, 0.2 \mu \mathrm{M} \mathrm{Na}_{2} \mathrm{MoO}_{4} \cdot 2 \mathrm{H}_{2} \mathrm{O}, 0.1 \mu \mathrm{M}$ $\mathrm{NiCl}_{2} \cdot 6 \mathrm{H}_{2} \mathrm{O}, 0.1 \mu \mathrm{M} \mathrm{H}_{3} \mathrm{BO}_{3}, 0.01 \mu \mathrm{M} \mathrm{CuCl}_{2} \cdot 2 \mathrm{H}_{2} \mathrm{O}$ ). For BONCAT labelling of growing cells, the minimal salts medium was used (to avoid competition for incorporation between AHA and methionine from the LB medium) but $40 \mathrm{~mm}$ sodium succinate or $40 \mathrm{mM}$ sodium succinate plus $40 \mathrm{~mm}$ glucose (for Salmonella Typhimurium) was added as a carbon source. All growth occurred at $30^{\circ} \mathrm{C}$, with shaking at $200 \mathrm{rpm}$ for liquid cultures. Liquid cultures were incubated in 30-mL universals with caps loosened.

\section{Starvation Survival Time Course}

Freezer stocks of bacteria were streaked to solid media and grown overnight, then 5-mL liquid cultures were started in LB Lennox. After $24 \mathrm{~h}$ in LB medium ("stationary phase"), cells were pelleted, the medium removed, and the pellet resuspended in $8 \mathrm{~mL}$ minimal medium without a carbon source. The amount of LB culture pelleted was normalized based on previously measured CFU/ $\mathrm{mL}$ in stationary phase in an effort to start all the starvation cultures with a total of $4 \times 10^{9}$ cells (a starting density of $0.5 \times 10^{8}$ $\mathrm{CFU} / \mathrm{mL}$ ), despite the different organisms reaching different $\mathrm{CFU} /$ $\mathrm{mL}$ (and different CFU/OD) at stationary phase. Then, $10 \mu \mathrm{L}$ of a 100,000 -fold dilution of each starvation culture was plated to count CFUs immediately after resuspension (day 0 ) and at 2.5- to 3 -day intervals for 31 days. Dilution factors were adjusted for some strains according to survival. Colonies were counted after 1-2 days of incubation ( $P$. atrosepticum colonies required 2 days to be visible while $E$. coli colonies were visible in less than a day). Water (0.2-0.6 mL) was added to each culture every 3-6 days to compensate for evaporation and maintain a culture volume equivalent to the starting volume, as the aliquots removed for CFU counts were of negligible volume. Two fully independent 31-day trials were conducted, and each trial began with either 3 or 4 culture replicates. The CFU count for each replicate at each timepoint was divided by the average number of CFUs across all day 0 replicates for the trial to calculate the fraction remaining for each replicate. All data are plotted together in Figure 1.

\section{BONCAT Labelling}

For BONCAT labelling, a $1.5-\mathrm{mL}$ aliquot of culture was removed to a small universal and AHA (Jena Bioscience cat. No. CLK-AA005) was added to a concentration of $200 \mu \mathrm{M}$. Cultures were incubated with AHA for $24 \mathrm{~h}$ (starving cultures) or $30 \mathrm{~min}$ (growing cultures). Following the labelling period, cells were pelleted, washed with PBS, resuspended in $100 \mu \mathrm{L}$ of $4 \%$ paraformaldehyde in PBS, and incubated for $30 \mathrm{~min}$ at room temperature to fix them. A series of 30-min incubations interspersed with washes with $500 \mu \mathrm{L}$ of PBS was carried out: first with ice-cold $70 \%$ ethanol (on ice) to permeabilise cells, then with $100 \mathrm{~mm}$ iodoacetamide (Sigma cat. No. I1149) in PBS to alkylate free cysteines in cells (to prevent their reaction with the fluorophore), then with dibenzocyclooctyne-functionalised fluorophore (DBCO-AF555, Jena Bioscience cat. No. CLK-093-1). Following this last incubation, cells were washed twice with $500 \mu \mathrm{L}$ of PBS then resuspended in a volume of PBS appropriate to the size of the cell pellet $(20-200 \mu \mathrm{L})$. Next, $1 \mu \mathrm{L}$ of this suspension was placed on an agarose pad $(1.5 \%$ agarose in PBS), constructed in a Gene Frame (Thermo Fisher cat. 
No. AB0577) on a microscope slide, and a cover slip added for imaging. The 28-day starved samples were taken from the same cultures used for CFU counts. The 2.5-day starved samples used for the BONCAT analysis were grown separately from the cultures used for CFU counts. In each case, two independent biological replicates were measured, and for each biological replicate, a noAHA control and two separate labelling replicates were performed. For some samples, the no-AHA control was slightly different between the two biological replicates, so data were not combined. All biological and labelling replicates are shown in online supplementary Figure S2, and the data from one experiment is shown in Figure 3.

\section{Microscopy}

Images were collected using a Zeiss Axio Imager M1 microscope with an HBO100 lamp and Zeiss Axiocam MRm3 1.4 megapixel CCD camera. A Plan-Neofluar 100x/1.30 Oil Ph 3 objective (with phase contrast) was used. The fluorescence channel images were collected using a Zeiss Filter Set 20 with an exposure time of $100 \mathrm{~ms}$. Zen Pro 2012 software was used to control the camera and microscope.

\section{Image Analysis}

All raw images used in these analyses are available for download as a zipped archive at https://www.ebi.ac.uk/biostudies/ studies/S-BSST596. Images were exported from the Zen Pro software either in the OME Tiff format or the.czi proprietary Zeiss format and imported into ImageJ [Schindelin et al., 2012] using the BioFormats package [Linkert et al., 2010]. Misalignment between the phase-contrast and fluorescence channels was corrected using the AlignFluorescentChannels macros that are part of the ObjectJ project [Vischer et al., 2015]. The MicrobeJ plugin [Ducret et al., 2016] was used to identify individual cells (mostly automated identification using the default method, with some manual editing to correct problems arising from clumps of cells) from each image and calculate their areas and average fluorescence intensities.

Statistical Analysis, Genome Analysis, and Figure Preparation

Rstudio and the ggplot 2 and Rcolorbrewer packages were used to generate the fraction surviving plots (Fig. 1), size boxplot (Fig. 2a), and BONCAT fluorescence distribution plots (Fig. 3). Microsoft Excel was used to generate the plot comparing average size to $\mathrm{CFU} / \mathrm{mL}$ at stationary phase (Fig. 2b). The phylogenetic tree was constructed using the Type (Strain) Genome Server [MeierKolthoff and Goker, 2019] and Interactive Tree of Life server [Letunic and Bork, 2019]. The whole-genome FASTA files of each organism were used as input, but the tree shown is based only on the $16 \mathrm{~S}$ sequences. Genome comparisons were made by using a custom perl script and the NCBI blast + suite of tools to carry out reciprocal best blast analysis of protein fasta files associated with the indicated genome accession numbers in Table 1. COG category analysis of the lists of genes shared by and unique to the highest- and lowest-survival strains made use of the 2020 update to the COG database [Galperin et al., 2020]. For the highest-survival strains, the $P$. aeruginosa $\mathrm{PAO} 1$ strain was represented in the COG database, so the PAO1 locus tags for the 321 genes of interest could be used directly to determine COG categories for these genes. For the lowest-survival strains, none of the genomes used in our study was present in the COG database, but a different $A$. baumannii strain (ATCC17978) was present. BLAST was used to retrieve the ATCC17978 locus tags for the genes of interest that were shared among the lowest-survival strains, and then this list of locus tags was used to determine COG categories. Six of the genes from the list did not have a BLAST hit in the ATCC17978 genome, so these were dropped from the COG analysis. Figures were prepared using Adobe Illustrator.

\section{Acknowledgments}

We would like to thank Sarah J. Coulthurst and Dianne K. Newman for their generous contributions of bacterial strains for this work.

\section{Conflict of Interest Statement}

The authors have no conflicts of interest to declare.

\section{Funding Sources}

This work was supported by the University of Dundee/Wellcome Trust Institutional Strategic Support Fund [204816/Z/16/Z], by a Springboard grant to M.B. from the Academy of Medical Sciences [SBF005/1096], and by a UKRI Future Leaders Fellowship (funded by the Medical Research Council) to M.B. [MR/ T041811/1]. The Springboard scheme is funded by the Wellcome Trust, the Government Department of Business, Energy, and Industrial Strategy, the British Heart Foundation, and Diabetes UK.

\section{Author Contributions}

M.B. designed the experiments, performed the experiments, analysed data, and wrote the manuscript. L.D. performed the experiments, analysed data, and contributed to editing of the manuscript.

\section{References}

Amy PS, Morita RY. Starvation-survival patterns of sixteen freshly isolated open-ocean bacteria. Appl Environ Microbiol. 1983;45(3): 1109-15.

Antunes LC, Visca P, Towner KJ. Acinetobacter baumannii: evolution of a global pathogen. Pathog Dis. 2014 Aug;71(3):292-301.
Arai H. Regulation and function of versatile aerobic and anaerobic respiratory metabolism in Pseudomonas aeruginosa. Front Microbiol. 2011;2:103.

Asakura H, Ishiwa A, Arakawa E, Makino S, Okada Y, Yamamoto S, et al. Gene expression profile of Vibrio cholerae in the cold stress-induced viable but non-culturable state. Environ Microbiol. 2007 Apr;9(4):869-79. 
Ayrapetyan M, Williams T, Oliver JD. Relationship between the viable but nonculturable state and antibiotic persister cells. J Bacteriol. 2018 Oct 15;200(20):200.

Babin BM, Bergkessel M, Sweredoski MJ, Moradian A, Hess S, Newman DK, et al. SutA is a bacterial transcription factor expressed during slow growth in Pseudomonas aeruginosa. Proc Natl Acad Sci USA. 2016 Feb 2;113(5): E597-605.

Bamford RA, Smith A, Metz J, Glover G, Titball RW, Pagliara S. Investigating the physiology of viable but non-culturable bacteria by microfluidics and time-lapse microscopy. BMC Biol. 2017 Dec 21;15(1):121.

Basta DW, Angeles-Albores D, Spero MA, Ciemniecki JA, Newman DK. Heat-shock proteases promote survival of Pseudomonas aeruginosa during growth arrest. Proc Natl Acad Sci USA. 2020 Feb 25;117(8):4358-67.

Basta DW, Bergkessel M, Newman DK. Identification of fitness determinants during energylimited growth arrest in Pseudomonas aeruginosa. mBio. 2017 Nov 28;8(6):e01170-17.

Bell KS, Sebaihia M, Pritchard L, Holden MT, Hyman LJ, Holeva MC, et al. Genome sequence of the enterobacterial phytopathogen Erwinia carotovora subsp. atroseptica and characterization of virulence factors. Proc Natl Acad Sci USA. 2004 Jul 27;101(30):11105-10.

Bouvet PJ, Grimont PA. Identification and biotyping of clinical isolates of Acinetobacter. Ann Inst Pasteur Microbiol. 1987 Sep-Oct 138(5):569-78.

Bergkessel M. Regulation of protein biosynthetic activity during growth arrest. Curr Opin Microbiol. 2020 Aug 25;57:62-9.

Bergkessel M, Basta DW, Newman DK. The physiology of growth arrest: uniting molecular and environmental microbiology. Nat Rev Microbiol. 2016 Aug 11;14(9):549-62.

Biselli E, Schink SJ, Gerland U. Slower growth of Escherichia coli leads to longer survival in carbon starvation due to a decrease in the maintenance rate. Mol Syst Biol. 2020 Jun, 16(6):e9478.

Blaby-Haas CE, Furman R, Rodionov DA, Artsimovitch I, de Crecy-Lagard V. Role of a Znindependent DksA in Zn homeostasis and stringent response. Mol Microbiol. $2011 \mathrm{Feb}$ 79(3):700-15.

Chen SL, Hung CS, Xu J, Reigstad CS, Magrini V, Sabo A, et al. Identification of genes subject to positive selection in uropathogenic strains of Escherichia coli: a comparative genomics approach. Proc Natl Acad Sci USA. 2006 Apr 11; 103(15):5977-82.

Chin-A-Woeng TFC, Bloemberg GV, van der Bi AJ, van der Drift KMGM, Schripsema J, Kroon B, et al. Biocontrol by phenazine- 1 carboxamide-producing Pseudomonas chlororaphis PCL1391 of tomato root rot caused by Fusarium oxysporum f. sp. radicis-lycopersici. MPMI. 1998;11(11):1069-77.
Dennis PP, Ehrenberg M, Bremer H. Control of rRNA synthesis in Escherichia coli: a systems biology approach. Microbiol Mol Biol Rev. 2004 Dec;68(4):639-68.

Dettman JR, Kassen R. Evolutionary genomics of niche-specific adaptation to the cystic fibrosis lung in Pseudomonas aeruginosa. Mol Biol Evol. 2021;38(2):663-75.

Dieterich DC, Lee JJ, Link AJ, Graumann J, Tirrell DA, Schuman EM. Labeling, detection and identification of newly synthesized proteomes with bioorthogonal non-canonical amino-acid tagging. Nat Protoc. 2007;2(3): $532-40$.

Ducret A, Quardokus EM, Brun YV. MicrobeJ, a tool for high throughput bacterial cell detection and quantitative analysis. Nat Microbiol. 2016 Jun 20;1(7):16077.

Erickson DW, Schink SJ, Patsalo V, Williamson JR, Gerland U, Hwa T. A global resource allocation strategy governs growth transition kinetics of Escherichia coli. Nature. $2017 \mathrm{Nov}$ 2;551(7678):119-23.

Farewell A, Diez AA, DiRusso CD, Nystrom T. Role of the Escherichia coli FadR regulator in stasis survival and growth phase-dependent expression of the uspa, fad, and fab genes. J Bacteriol. 1996;178(22):6443-50.

Fernandez-Coll L, Maciag-Dorszynska M, Tailor K, Vadia S, Levin PA, Szalewska-Palasz A, et al. The absence of (p)ppGpp renders initiation of Escherichia coli chromosomal DNA synthesis independent of growth rates. mBio. 2020 Mar 10;11(2):e03223-19.

Finkel SE. Long-term survival during stationary phase: evolution and the GASP phenotype. Nat Rev Microbiol. 2006 Feb;4(2):113-20.

Finkel SE, Kolter R. Evolution of microbial diversity during prolonged starvation. Proc Natl Acad Sci USA. 1999 Mar 30;96(7):4023-7.

Flyg C, Kenne K, Boman HG. Insect pathogenic properties of Serratia marcescens: phage-resistant mutants with a decreased resistance to Cecropia immunity and a decreased virulence to Drosophila. J Gen Microbiol. 1980 Sep; 120(1):173-81.

Galperin MY, Wolf YI, Makarova KS, Vera Alvarez R, Landsman D, Koonin EV. COG database update: focus on microbial diversity, model organisms, and widespread pathogens. Nucleic Acids Res. 2021;49(D1):D274-81.

Gefen O, Fridman O, Ronin I, Balaban NQ. Direct observation of single stationary-phase bacteria reveals a surprisingly long period of constant protein production activity. Proc Natl Acad Sci USA. 2014;111(1):556-61.

Gorshkov V, Islamov B, Mikshina P, Petrova O, Burygin G, Sigida E, et al. Pectobacterium atrosepticum exopolysaccharides: identification, molecular structure, formation under stress and in planta conditions. Glycobiology. 2017 Nov 1;27(11):1016-26.

Gottesman S. Trouble is coming: signaling pathways that regulate general stress responses in bacteria. J Biol Chem. 2019 Aug 2;294(31): $11685-700$
Gourse RL, Chen AY, Gopalkrishnan S, SanchezVazquez P, Myers A, Ross W. Transcriptional responses to ppGpp and DksA. Annu Rev Microbiol. 2018;72:163-84.

Harding CM, Hennon SW, Feldman MF. Uncovering the mechanisms of Acinetobacter baumannii virulence. Nat Rev Microbiol. 2018 Feb;16(2):91-102.

Hatzenpichler R, Krukenberg V, Spietz RL, Jay ZJ. Next-generation physiology approaches to study microbiome function at single cell level. Nat Rev Microbiol. 2020 Apr;18(4):241-56.

Hauryliuk V, Atkinson GC, Murakami KS, Tenson $\mathrm{T}$, Gerdes K. Recent functional insights into the role of (p)ppGpp in bacterial physiology. Nat Rev Microbiol. 2015 May;13(5):298309.

He J, Baldini RL, Deziel E, Saucier M, Zhang Q, Liberati NT, et al. The broad host range pathogen Pseudomonas aeruginosa strain PA14 carries two pathogenicity islands harboring plant and animal virulence genes. Proc Natl Acad Sci USA. 2004 Feb 24;101(8):25305.

Hobbie JE, Hobbie EA. Microbes in nature are limited by carbon and energy: the starvingsurvival lifestyle in soil and consequences for estimating microbial rates. Front Microbiol. 2013;4:324.

Holloway BW. Genetic recombination in Pseudomonas aeruginosa. J Gen Microbiol. 1955 Dec;13(3):572-81.

Kazakov AE, Rodionov DA, Alm E, Arkin AP, Dubchak I, Gelfand MS. Comparative genomics of regulation of fatty acid and branched-chain amino acid utilization in Proteobacteria. J Bacteriol. 2009 Jan;191(1): 52-64.

Kraemer JA, Sanderlin AG, Laub MT. The stringent response inhibits DNA replication initiation in E. coli by modulating supercoiling of oriC. mBio. 2019 Jul 2;10(4):e01330-19.

Lee KM, Go J, Yoon MY, Park Y, Kim SC, Yong $\mathrm{DE}$, et al. Vitamin B12-mediated restoration of defective anaerobic growth leads to reduced biofilm formation in Pseudomonas aeruginosa. Infect Immun. 2012 May;80(5): $1639-49$.

Letunic I, Bork P. Interactive Tree Of Life (iTOL) v4: recent updates and new developments. Nucleic Acids Res. 2019 Jul 2;47(W1):W256W59.

Linkert M, Rueden CT, Allan C, Burel JM, Moore W, Patterson A, et al. Metadata matters: access to image data in the real world. J Cell Biol. 2010 May 31;189(5):777-82.

Loutet SA, Valvano MA. A decade of Burkholderia cenocepacia virulence determinant research. Infect Immun. 2010 Oct;78(10):4088100

Mathee K. Forensic investigation into the origin of Pseudomonas aeruginosa PA14 - old but not lost. J Med Microbiol. 2018 Aug;67(8): 1019-21. 
Meier-Kolthoff JP, Goker M. TYGS is an automated high-throughput platform for state-ofthe-art genome-based taxonomy. Nat Commun. 2019 May 16;10(1):2182.

Moreno-Gamez S, Kiviet DJ, Vulin C, Schlegel S, Schlegel K, van Doorn GS, et al. Wide lag time distributions break a trade-off between reproduction and survival in bacteria. Proc Natl Acad Sci USA. 2020 Aug 4;117(31):18729-36.

Müller-Santos M, Koskimaki JJ, Alves LPS, de Souza EM, Jendrossek D, Pirttila AM. The protective role of $\mathrm{PHB}$ and its degradation products against stress situations in bacteria. FEMS Microbiol Rev. 2020. doi: 10.1093/femsre/fuaa058.

Pechter KB, Yin L, Oda Y, Gallagher L, Yang J, Manoil C, et al. Molecular basis of bacterial longevity. mBio. 2017 Nov 28;8(6):e01726-17.

Price-Whelan A, Dietrich LE, Newman DK. Pyocyanin alters redox homeostasis and carbon flux through central metabolic pathways in Pseudomonas aeruginosa PA14. J Bacteriol. 2007 Sep;189(17):6372-81.

Prieto A, Escapa IF, Martinez V, Dinjaski N, Herencias C, de la Pena F, et al. A holistic view of polyhydroxyalkanoate metabolism in Pseudomonas putida. Environ Microbiol. 2016 Feb;18(2):341-57.

Rajkovic A, Ibba M. Elongation factor P and the control of translation elongation. Annu Rev Microbiol. 2017 Sep 8;71:117-31.

Ratzke C, Gore J. Modifying and reacting to the environmental $\mathrm{pH}$ can drive bacterial interactions. PLoS Biol. 2018 Mar;16(3):e2004248.

Rodionov DA, Vitreschak AG, Mironov AA, Gelfand MS. Comparative genomics of the vitamin B12 metabolism and regulation in prokaryotes. J Biol Chem. 2003 Oct 17;278(42): 41148-59.

Römling U, Fiedler B, Bosshammer J, Grothues $D$, Greipel J, von der Hardt H, et al. Epidemiology of chronic Pseudomonas aeruginosa infections in cystic fibrosis. J Infect Dis. 1994 Dec;170(6):1616-21.

Ruhal R, Kataria R, Choudhury B. Trends in bacterial trehalose metabolism and significant nodes of metabolic pathway in the direction of trehalose accumulation. Microb Biotechnol. 2013 Sep;6(5):493-502.
Sanchez-Vazquez P, Dewey CN, Kitten N, Ross W, Gourse RL. Genome-wide effects on Escherichia coli transcription from ppGpp binding to its two sites on RNA polymerase. Proc Natl Acad Sci USA. 2019 Apr 23;116(17): 8310-9.

Schindelin J, Arganda-Carreras I, Frise E, Kaynig V, Longair M, Pietzsch T, et al. Fiji: an opensource platform for biological-image analysis. Nat Methods. 2012 Jun 28;9(7):676-82.

Schink SJ, Biselli E, Ammar C, Gerland U. Death rate of E. coli during starvation is set by maintenance cost and biomass recycling. Cell Syst. 2019 Jul 24;9(1):64-73.e3.

Sekar K, Linker SM, Nguyen J, Grunhagen A, Stocker R, Sauer U. Bacterial glycogen provides short-term benefits in changing environments. Appl Environ Microbiol. 2020 Apr 17;86(9):86

Sezonov G, Joseleau-Petit D, D'Ari R. Escherichia coli physiology in Luria-Bertani broth. J Bacteriol. 2007 Dec;189(23):8746-9.

Siddiqee MH, Henry R, Deletic A, Bulach DM, Coleman RA, McCarthy DT. Salmonella from a microtidal estuary are capable of invading human intestinal cell lines. Microb Ecol. 2020 Feb;79(2):259-70.

Sonnleitner E, Valentini M, Wenner N, Haichar FZ, Haas D, Lapouge K. Novel targets of the $\mathrm{CbrAB} / \mathrm{Crc}$ carbon catabolite control system revealed by transcript abundance in Pseudomonas aeruginosa. PLoS One. 2012;7(10): e44637.

Takano S, Pawlowska BJ, Gudelj I, Yomo T, Tsuru S. Density-dependent recycling promotes the long-term survival of bacterial populations during periods of starvation. mBio. 2017 Feb 7;8(1):e02336-16.

Tavares M, Kozak M, Balola A, Coutinho CP, Godinho CP, Hassan AA, et al. Adaptation and survival of Burkholderia cepacia and B. contaminans during long-term incubation in saline solutions containing benzalkonium chloride. Front Bioeng Biotechnol. 2020;8:630.

Typas A, Becker G, Hengge R. The molecular basis of selective promoter activation by the sigmaS subunit of RNA polymerase. Mol Microbiol. 2007 Mar;63(5):1296-306.

Vadia S, Levin PA. Growth rate and cell size: a reexamination of the growth law. Curr Opin Microbiol. 2015 Apr;24:96-103.

Vadia S, Tse JL, Lucena R, Yang Z, Kellogg DR, Wang JD, et al. Fatty acid availability sets cell envelope capacity and dictates microbial cell size. Curr Biol. 2017 Jun 19;27(12):1757-e5. van Overbeek LS, Eberl L, Givskov M, Molin S, van Elsas JD. Survival of, and induced stress resistance in, carbon-starved Pseudomonas fluorescens cells residing in soil. Appl Environ Microbiol. 1995;61(12):4202-8.

Venturi V. Control of rpoS transcription in Escherichia coli and Pseudomonas: why so different? Mol Microbiol. 2003;49(1):1-9.

Vischer NO, Verheul J, Postma M, van den Berg van Saparoea B, Galli E, Natale P, et al. Cell age dependent concentration of Escherichia coli divisome proteins analyzed with ImageJ and ObjectJ. Front Microbiol. 2015;6:586.

Wang B, Dai P, Ding D, Del Rosario A, Grant RA, Pentelute BL, et al. Affinity-based capture and identification of protein effectors of the growth regulator ppGpp. Nat Chem Biol. 2019 Feb;15(2):141-50.

Wanner BL, Gottesman M, Gottesman M. Overlapping and separate controls on the phosphate regulon in Escherichia coli K12. J Mol Biol. 1983;166(3):283-308.

Wargo MJ. Homeostasis and catabolism of choline and glycine betaine: lessons from Pseudomonas aeruginosa. Appl Environ Microbiol. 2013 Apr;79(7):2112-20.

Westfall CS, Levin PA. Comprehensive analysis of central carbon metabolism illuminates connection setween nutrient availability, growth rate, and cell morphology in Escherichia coli. PLoS Genet. 2018 Feb; 14(2):e1007205.

Yin L, Ma H, Nakayasu ES, Payne SH, Morris DR, Harwood CS. Bacterial longevity requires protein synthesis and a stringent response. mBio. 2019 Oct 15;10(5):e02189-19.

Zeidler S, Müller V. The role of compatible solutes in desiccation resistance of Acinetobacter baumannii. Microbiologyopen. 2019 May; 8(5): $\mathrm{e} 00740$.

Zeidler S, Müller V. Unusual deprivation of compatible solutes in Acinetobacter baumannii. Environ Microbiol. 2020 Apr;22(4):1370-80.

Zinser ER, Kolter R. Mutations enhancing amino acid catabolism confer a growth advantage in stationary phase. J Bacteriol. 1999;181(18): $5800-7$.

Zinser ER, Kolter R. Prolonged stationary-phase incubation selects for lrp mutations in Escherichia coli K-12. J Bacteriol. 2000;182(15): 4361-5. 